\title{
Health complaints and working conditions experienced in relation to work and age
}

\author{
J P J Broersen, B C H de Zwart, F J H van Dijk, T F Meijman, M van Veldhoven
}

\begin{abstract}
Objectives-The main objective is to describe the potential health and work problems of the aging employees in the Dutch working population. In this way, we can identify groups at extra risk of specific health problems.
\end{abstract}

Methods-In The Netherlands, occupational health services gather questionnaire data about work and health as part of periodical occupational health surveys (POHSs). These data from the POHSs of complaints about health and working conditions, aggregated into occupational groups and age categories, are used to provide indications for groups at extra risk of specific health problems. These problems are assessed by overviews of the relation between age and complaints about health and working conditions.

Results-Almost all of the health questions show an increase in health complaints with increasing age. White collar workers, especially the high grade white collar workers, usually have lower complaint percentages on health questions than blue collar workers. Female employees have relatively high complaint percentages on the health questions. Differences between occupational groups in the complaints about work and working conditions reflect the differences in work demands and exposure. The relation between age and work complaints is generally inconsistent and weak. The complaint percentages on work questions of female employees tend to be equal to or lower than those of the male employees. Conclusions-The absence of a clear increase of work complaints with advancing age in the presence of a decrease in health and working capacity may be explained by a selective turnover in the working population, especially in demanding occupations. To enhance the work participation of older employees it may be necessary to reduce the work demands and to increase decision latitude.

(Occup Environ Med 1996;53:51-57)

Keywords: work related diseases; working conditions; information system; periodical occupational health survey; aging

The aging process in people generally leads to changes in the work capacity. Examples of those changes are the decrease of the physical capacity to work ${ }^{1-3}$ and the slowing in cognitive performance in the elderly, especially for complex and difficult tasks. ${ }^{45}$ According to the model "work demands-work capacity" of van Dijk et al, ${ }^{6}$ a decrease of the work capacity may lead to the disruption of the balance between work demands and work capacity (see also Shephard ${ }^{2}$ ). Chronic overload may cause health complaints and absenteeism, and in the long term even disablement. This may partly explain the increase of many health problems, chronic diseases, and impairment with increasing age. In 1992, for example, the incidence of new cases of disablement among the workforce in The Netherlands was $22 \cdot 6 / 1000$ workers aged 45-64 v 5.0/1000 workers aged $15-24 .^{7}$

The age distribution of the Dutch workforce is changing: it is an aging population. Therefore, the number of workers failing to cope with work demands because of health and age related impairments of their work capacity will probably rise in the years to come, especially in occupations with high task demands. This work disablement will in general not occur abruptly: it will be preceded by a period of increased effort to cope with the demands of specific tasks and health complaints. By means of a questionnaire we might be able to determine which health complaints are most common and which task aspects impose the greatest demands on the aging worker.

In The Netherlands, regional occupational health services (OHSs) take care of the health and wellbeing of the employees of the associated companies. They have been collecting data as part of the periodical occupational health surveys (POHSs). Since 1981 a standard questionnaire for POHSs is available, that is currently being used by most of OHSs. ${ }^{8}$ The questionnaire consists of two parts: one about several health complaints and medical treatment for specific diseases and the other with questions about the working conditions and work demands experienced. 9 The questionnaire is not aimed at a specific health problem or loading work factor, but covers a broad range of themes about health and work problems, relevant to a variety of occupations.

The data from the POHSs can be aggregated because the questionnaire data have been collected in a uniform manner. Data from several companies can be merged for the description of the health and working conditions of groups of employees-for example, the employees in a specific occupational group $^{10}$ or in an age category. The results can
Amsterdam,

The Netherlands.

Accepted 17 July 1995 
be used to indicate specific health problems and working conditions that create an extra risk.

In the present study we attempted to picture the age related differences in health and work capacity of employees. We therefore generated overviews of the prevalence of complaints of employees, categorised by age and social class. ${ }^{11}$ Male and female employees were analysed separately for four reasons. Firstly, because of biological differences-for example, the differing capacities of men and women. Secondly, because of differences in working hours and in the load at home due to household and child care duties. Thirdly, because many women's careers are interrupted by periods of maternity leave and years away from work for taking care of young children. Fourthly, the occupational composition of the occupational groups may differ between the male and female employees-for example, there are many cleaners among the female blue collar workers $v$ many factory workers among the male blue collar workers. The curves of the complaints with age of the female employees are expected to be more ragged than the curves of the male employees.

In this article, some examples of the results of the study already mentioned will be presented. Although the nature of the study was descriptive and exploratory, some general observations may be derived from the results. An indication of the relation between work and the health complaints can be derived from the differences between occupations. ${ }^{10} \mathrm{We}$ expected the prevalences of health complaints generally to increase with age. From the overviews for each occupational group, age category, and sex in the present study we could obtain signs of groups at extra risk of specific health problems, which was one of the purposes of this study. If additional evidence of those health risks was available from other sources, specific measures could be proposed, otherwise further research will be needed. Because of the nature of the subject matter, most items on work and working conditions will differ between occupational groups. Our expectations about the relation between age and the percentages of complaints about work are ambiguous. On the one hand, we expected the work complaints to increase with age, as some capacities decrease and the prevalence of

Number of employees in the POHS's file for age, sex, and social group

\begin{tabular}{lrrrrr}
\hline & Age $(y)$ & & & & \\
\cline { 2 - 6 } $\begin{array}{l}\text { Sex and social } \\
\text { group }\end{array}$ & $\leqslant 29$ & $30-39$ & $30-49$ & $\geqslant 50$ & All ages \\
\hline Female employees: & & & & & \\
Blue collar & 435 & 308 & 304 & 140 & 1187 \\
Low white collar & 1226 & 425 & 242 & 92 & 1985 \\
Medium white collar & 312 & 187 & 95 & 38 & 632 \\
High white collar & 27 & 26 & 9 & 5 & 67 \\
Medium + high white collar & 339 & 213 & 104 & 43 & 699 \\
Total female employees & 2000 & 946 & 650 & 275 & 3871 \\
Male employees: & & & & & \\
Blue collar & 1677 & 1504 & 1369 & 894 & 5444 \\
Low white collar & 441 & 478 & 398 & 285 & 1602 \\
Medium white collar & 325 & 649 & 616 & 396 & 1986 \\
High white collar & 72 & 399 & 476 & 288 & 1235 \\
Total male employees & 2515 & 3030 & 2859 & 1863 & 10267 \\
\hline
\end{tabular}

several health problems increase with age. On the other hand, older employees may be transferred to other less strenuous work places, and may use more efficient strategies, or many older employees may be less sensitive to some working conditions-for example, be less affected by noise because of hearing loss. Moreover, the group of older employees may be a relatively strong group through health related turnover. From the shape of the curve of the work complaints with age we can infer the relative strength of these two opposite influences of age.

We shall discuss the limitations of the application of the results-for example, the problems caused by the cross sectional nature of the data collection. On the basis of the results we shall try to formulate some proposals for further research, which may produce more understanding of the development of work related complaints and diseases and disablement. This could be a first step in the prevention of these phenomena, and may contribute to the work participation of aging employees in the future.

\section{Materials and methods}

Questionnaire data from the POHSs from more than 14000 employees were used. The questionnaire comprises 117 questions about health and 55 about work. The response structure of the questions was a dichotomy: a complaint was either present or absent.

The POHSs were executed by each company within the regional OHS "WestBrabant" in the period 1985-91. The procedures of the execution of the POHSs by the OHS "West-Brabant" were fully described by Jenniskens, ${ }^{12}$ and showed close resemblance to the procedures of the OHS "OostGelderland" as described by Weel et al. ${ }^{9}$ The POHSs at the OHS "West-Brabant" were applied to each company; all employees of a company were invited, but participation was not obligatory. The overall response was $86 \%$. The interval between two POHSs is generally three to five years. In this study, only the first POHS of employees who participated more than once was used. Occupations were coded according to the classification of occupations of the Dutch Central Bureau of Statistics (CBS) in a four digit code, ${ }^{13}$ and were classified into four social groups ${ }^{14}$ : blue collar workers; low grade white collar workers; medium grade white collar workers; high grade white collar workers.

Age was categorised into four groups. The table shows the number of the employees according to age category, sex, and social group. The number of high grade white collar women was relatively small, and, therefore, we combined the data from medium and high grade white collar women. Even then, the number of male employees is greater than the number of female employees in most of the cells of the table. This makes the prevalences of complaints of the men generally more stable, and for that reason most of the figures in this article are based on the results of the men. 
Figure 1 Answers to the question "Do you regularly have pain or stiffness in the back?" of male $(A)$ and female (B) employees by social group and by age.

Figure 2 Answers to the question "Do you have complaints about seeing (even if you wear contact lenses or glasses)?" of male employees in four social groups by age.

Figure 3 Answers to the question "Are you allergic to something?" of male employees in four social groups by age.

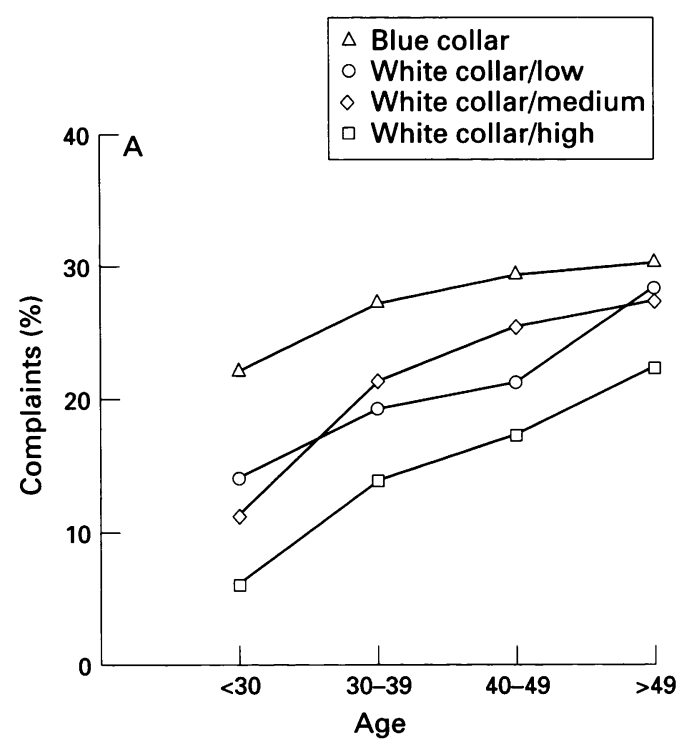

\section{Results}

GENERAL REMARKS

The number of questions is too large to present and discuss each separately. In this section, we will only give a broad outline of the results. A distinction is made between the questions about health and those about working conditions.

Figures 1 to 8 are examples of the results. A short description of the question is given in the legend of each figure. The horizontal axis represents the four age categories, and the vertical axis the percentage of complaints. The maxi-
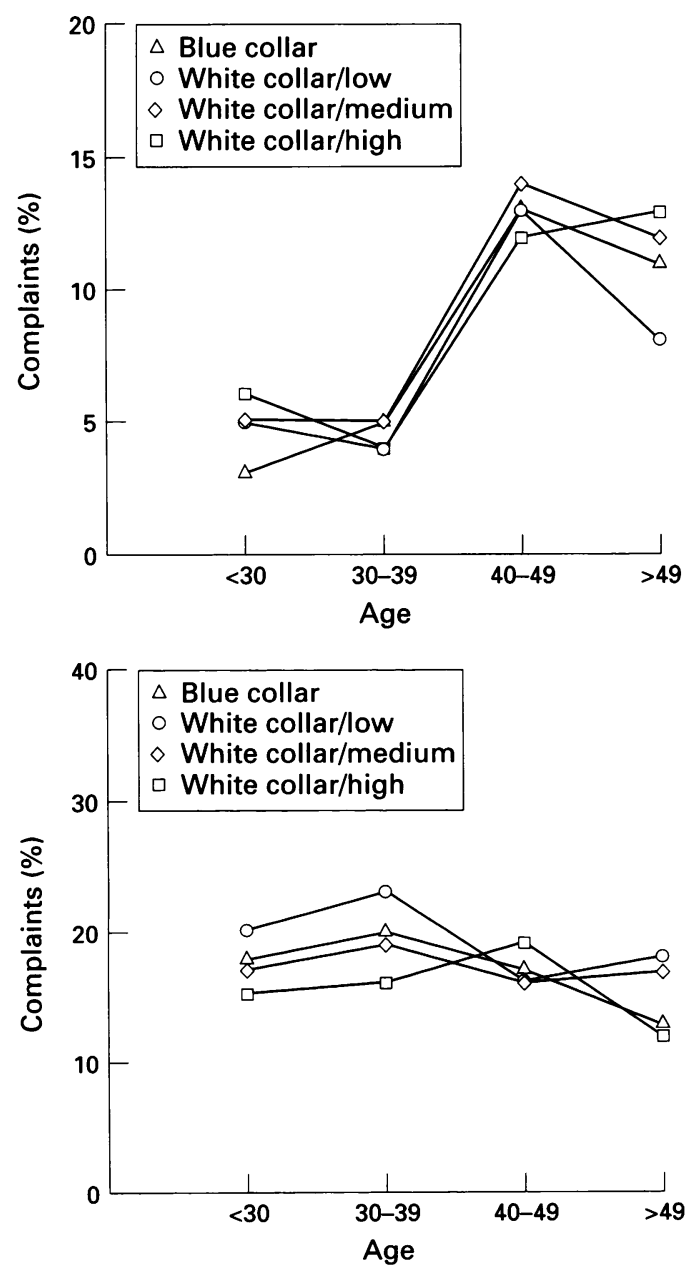

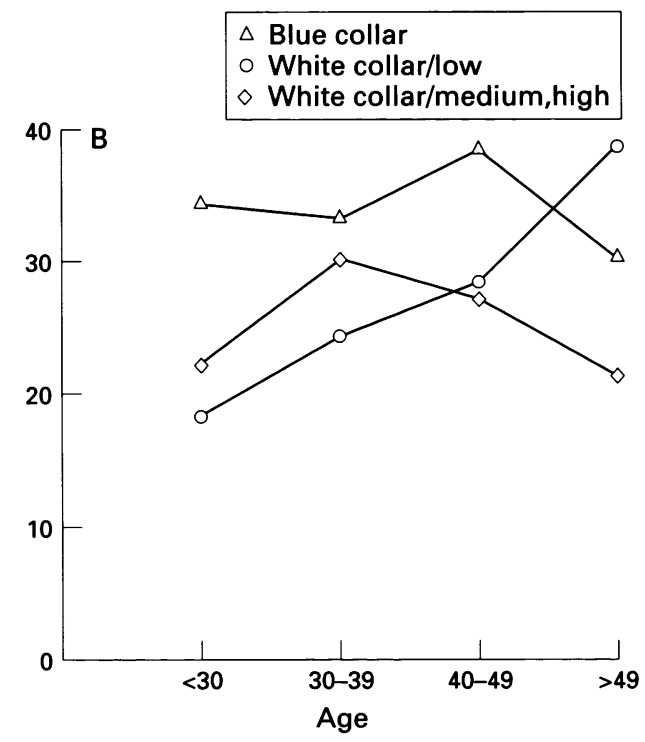

mum on the scale of the vertical axis depends on the range of the percentages, and, therefore, differs between questions. Every figure for the men contains four curves and for the women three curves, one for each social group. These figures allow a prompt impression of the development of complaints with age.

\section{ITEMS ABOUT HEALTH}

Figure 1 shows the results of the question about backache for men and women. The complaint percentages of all four groups of men increased with age. The male blue collar workers showed the highest complaint percentages, especially in the youngest age groups, whereas the high grade white collar workers showed the lowest. The increase in the complaint percentages of the male blue collar workers with age seems to be less steep than those of the white collar groups. The pattern of figure $1(B)$ with the female employees is more difficult to describe. The female low grade white collar group started off with the lowest complaint percentages in the two youngest age categories, but through an almost constant slope they ended with the highest score in the oldest age category. The medium and high grade white collar employees showed a decrease in complaint percentages after an initial rise before 40 . The complaint percentages of the female blue collar workers decreased slightly before 40 , then increased until 50, and finally dropped again to their lowest value in the oldest age group.

These features of figure $1(A)$ can be observed, in various degrees, in the curves of many questions about health complaints of the male employees. Only the item about visual complaints (fig 2) and the question concerning allergy (fig 3) showed a distinctively different picture. The differences between the social groups in complaint percentages on those two questions were small and inconsistent between the four age groups. The complaints about vision rose sharply after 40, corresponding with the normal decline in vision in a healthy population. ${ }^{15}$ After a slight increase up to 40 , the complaints about allergy decreased with age. 
Figure 4 Answers to the question "Did you receive medical treatment for heart disease in the last five years?" of male employees in four social groups by age.

Figure 5 Answers to the question "Is your work physically very strenuous" of female $(A)$ and male (B) employees by social group and by age.
Figure 6 Answers to the question "Is your work mentally very strenuous?" of female $(A)$ and male (B) employees by social group and by age.

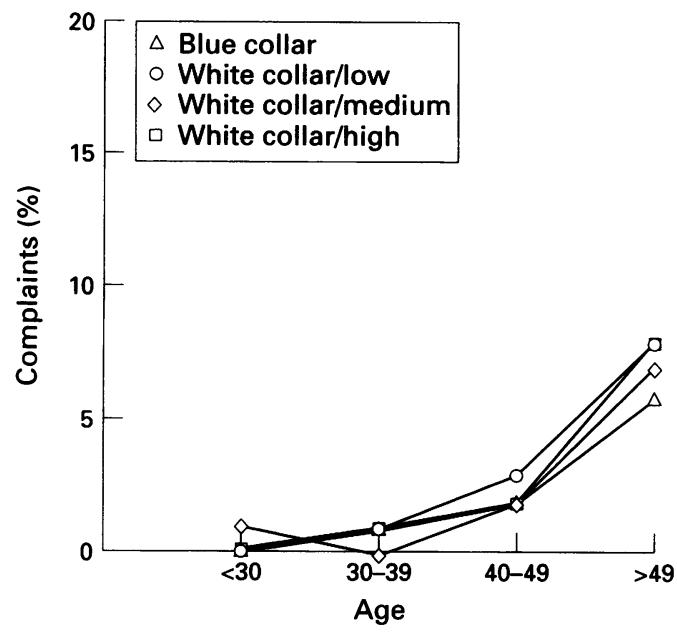

The complaint percentages on the health questions of the female employees were in general higher than those of the male employees of the same age and social group. The patterns tended to be more irregular, probably because of the smaller size of the groups. The patterns of the complaint percentages of the female employees for the questions on
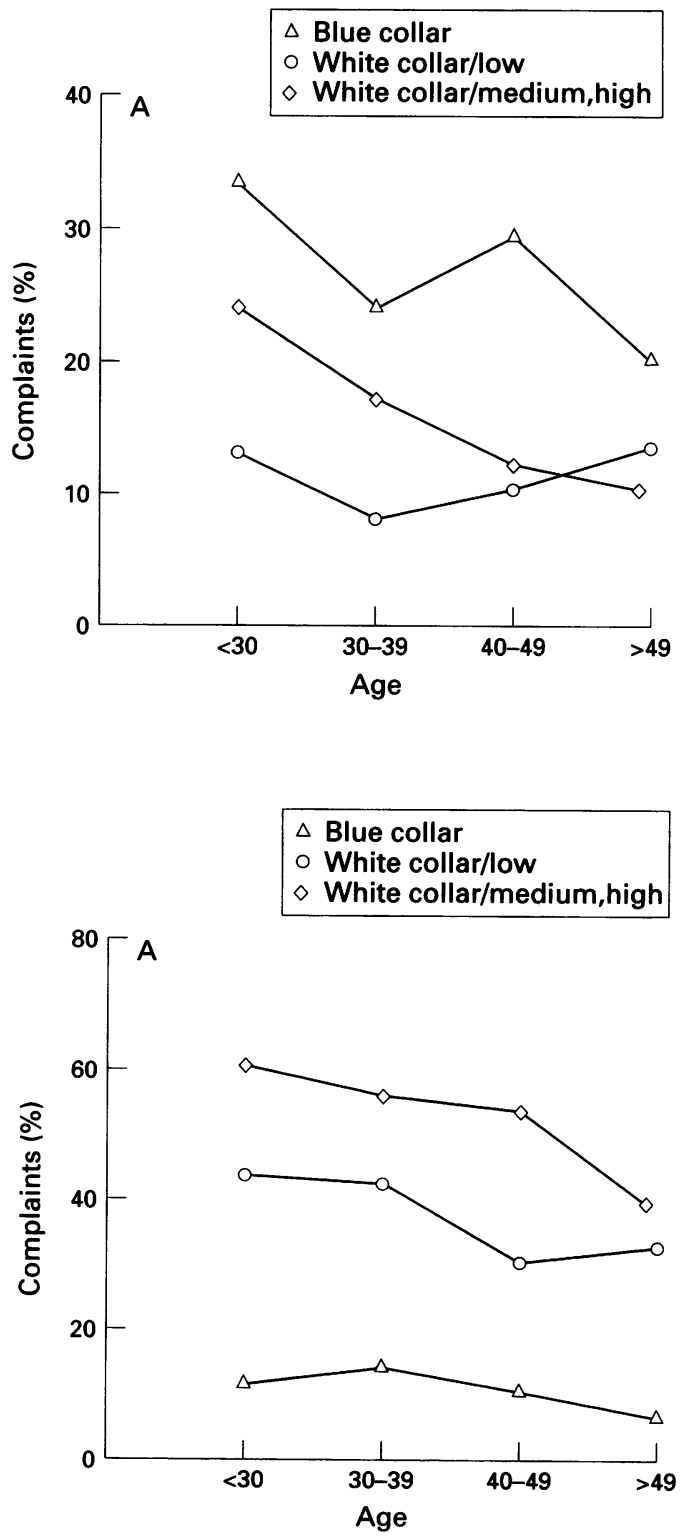

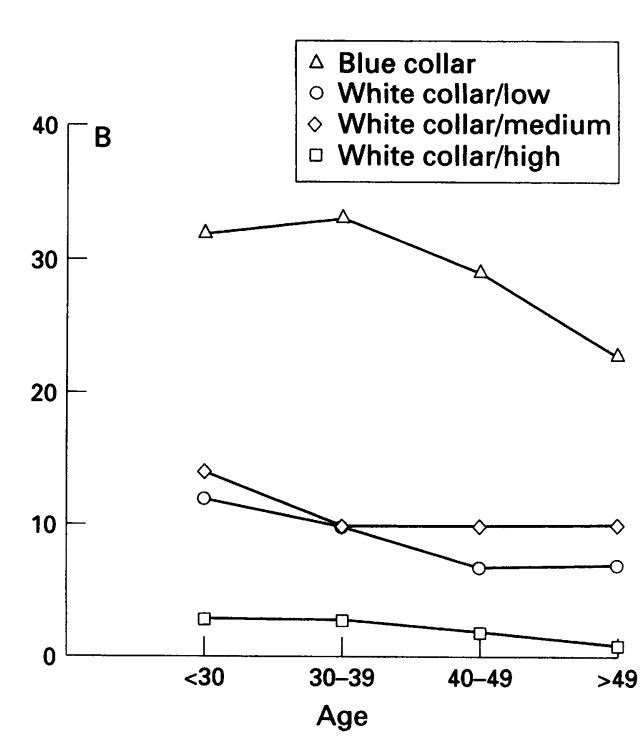

complaints about vision and allergy resembled those of the male employees in figures 2 and 3 (results of the female employees not shown).

Three of the questions about medical treatment in the preceding five years of both the male and the female employees resemble the general picture of the health complaints-for example, the question about medical treatment for a serious accident and two questions about medical treatment for complaints of the musculoskeletal system. The other seven questions about medical treatment differed from the general picture of the health complaints, mainly in the differences between the social groups. As an example, figure 4 shows the results from the question about medical treatment for heart disease in the preceding five years for the male employees. The differences between the social groups were relatively small and inconsistent. In figure 4, the slope of the curve increased sharply in the last age groups. This feature was absent in the results of this question from the female employees (not shown here), and was not common to all of the questions about medical treatment.

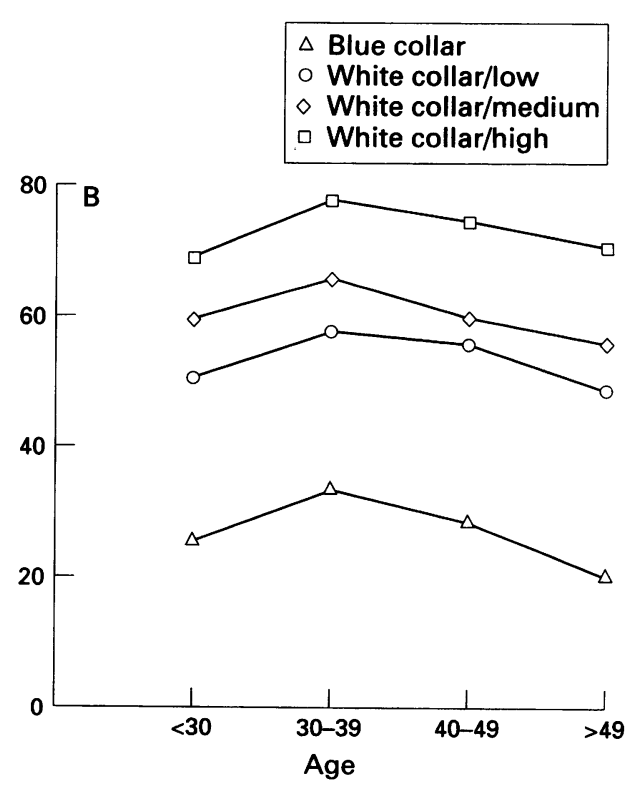


Figure 7 Answers to the question "Do you from lack of fresh air in your work?" of male employees in four social groups by age. experience much hindrance
Figure 8 Answers to the question "Are you hindered in your work by the absence of fellow workers?" of male employees in four social groups by age.
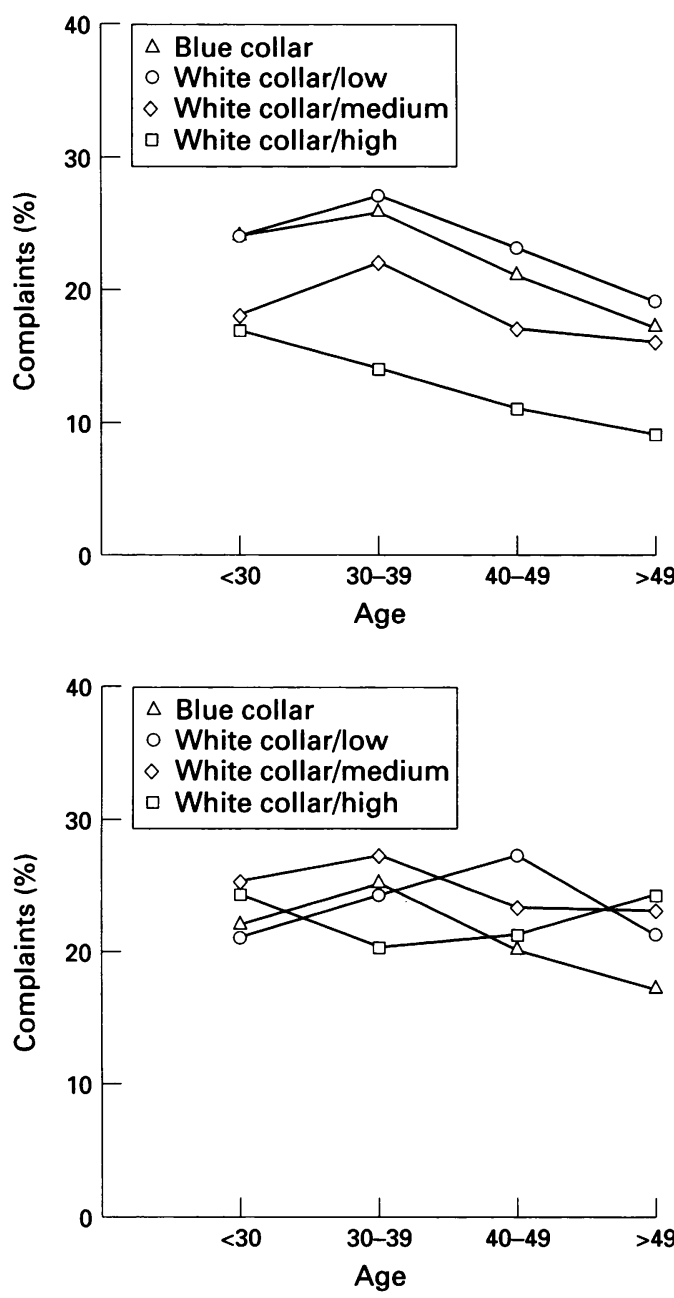

Figure 9 Comparison of relation between age and the complaints (\%) about physically very strenuous work of male employees in the POHSs and the CBS/LSO-studies.

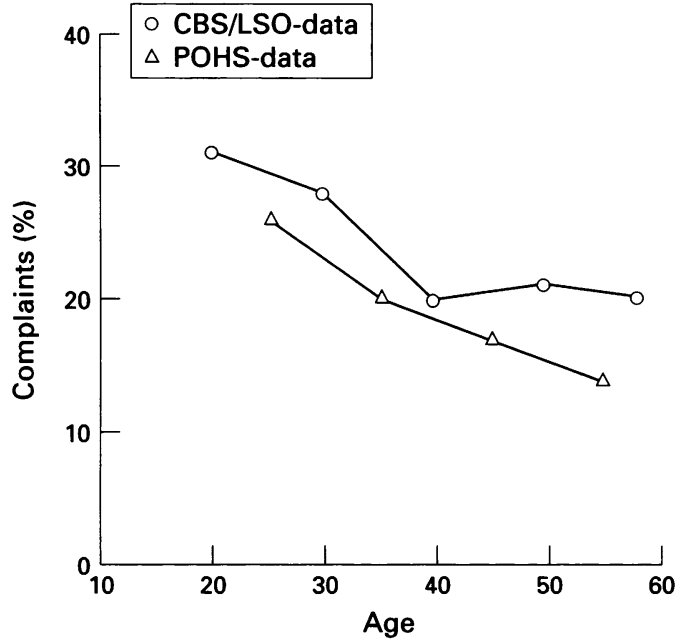

Almost all of the figures from the questions about health resembled each other to some degree. Most of the answers showed a rise in complaints with increasing age. When differences between social groups were present, the blue collar workers usually had a relatively high complaint percentage, whereas the high grade white collar workers reported a low percentage, and the percentages of the other two social groups lay in between. Female employees scored relatively high on the health complaints.
QUESTIONS ABOUT WORK

Most questions about work showed large differences between social groups. These differences might be expected, because the employees were classified into those groups according to the characteristics of their work. For example, a relatively high percentage of the blue collar workers experienced hindrance of physical, chemical, and climatological factors (fig 5: "is your work physically very strenuous?"), and high grade white collar workers often reported pressure of time and high demands from mental tasks (fig 6: "Is your work mentally very strenuous?").

The relations between the complaint percentages and age on the work questions were in general not as strong and consistent as the relations on the health questions. Many questions showed an inverted $U$ curve, with an increase from the age group under 30 to the group aged 30 to 39 years and a decrease in the older age categories (fig $6(B)$ ). In several questions, this phenomenon was combined with a slight overall decrease of the complaint percentages - for example, the question on complaints about a lack of fresh air for male employees (fig 7). In other questions, the relation between the complaint percentages and age was weak and inconsistent between social groups-for example, the question about hindrance in the work by the absence of fellow workers (fig 8 , male employees). The results from the work questions of the female employees resembled those of the male employees. On some of the work questions, the female employees showed higher complaint percentages than the male employees of the same age and social group, but for most questions their scores were about the same or lower than the percentages of the male employees.

The results of the questions about work with respect to social groups were as expected: the social group exposed to the highest levels of work demands or the highest exposure to adverse working conditions expressed more complaints on the corresponding work questions. The relation between age and the complaint percentages on the work questions was mostly weak and inconsistent. A slight decrease in complaint percentages after 40 was found in many of the answers of both the male and female employees, other patterns were very diverse and could hardly be summarised in one general description.

\section{Discussion}

In general, the health and the work capacity of employees decreased with advancing age. As expected, the complaint percentages on most of the health questions increased in the older age categories. The prevalences of the complaints about work and working conditions did not increase in a comparable degree. Presumably, this can be explained by a selective turnover in the working population, especially in demanding occupations. ${ }^{10}$ According to this line of reasoning, the aging employees in very strenuous working situations or with a lower than average work capacity and with 
health problems are more likely to change job and leave their jobs because of disability. ${ }^{16}$ The remaining employees are supposed to have a relatively high work capacity and work in less strenuous working situations. This may be an explanation of the decrease of the work complaints in the older age categories, as well as of the levelling off of the slopes of the curves of some of the health complaints in the oldest age categories, especially in the curves of the blue collar workers. The problem of health related selection, which may be one of the causes of the low rate of work participation of the aging employee, is growing. In The Netherlands, the male work participation rate in the age category of $60-64$ years decreased from $85 \%$ in 1960 to $40 \%$ in $1985 .{ }^{17}$ The effects of selection, partly caused by the cross sectional nature of the data, limits the possibilities of use of the data to study the development of health problems, especially chronic diseases and diseases caused by prolonged exposure to adverse working conditions. ${ }^{18}$ The differences in complaint percentages between social groups, as presented in this article, is probably an underestimation of the real influence of work and working conditions on the prevalence of health problems and effort to cope with working demands. ${ }^{910}$

There are two other possible explanations for the absence of a rise of the work complaints with age. The first assumes that the older employees have a different frame of reference to judge the work demands and the working conditions. Although coping with the present working demands and the working conditions costs them much effort, partly because of health problems, they might think that the present working situations are not as bad as they used to be in the past. A second explanation might be that all employees judge their working situation relative to other occupations they know, and not from the point of view of their present capacities. According to this line of reasoning, blue collar workers more often complained about vibration not because they experienced negative effects and hindrance of vibration, but because they, objectively, were exposed to a higher vibration dose in their work than other employees such as white collar workers. This judgement will be independent of the capacities of the employees and, therefore, also independent of age. These two last explanations may play a part in the results of the work questions, but are in our opinion of less importance than the selection of employees.

In this study, data from one regional OHS in The Netherlands were used. The group of employees in this study was not a random sample of the Dutch work force, or of any working population abroad. This does not imply that the results of this study are not representative of the general patterns present in those populations, but large scale surveys of subjective health and working conditions experienced are rare in The Netherlands, and only the data collected in some surveys of the Dutch Central Bureau of Statistics are comparable with the information from the present study. In the surveys of the life situation of the Dutch general population (LSO surveys), some questions about general health and work were $^{\text {included }}{ }^{19}(n=6061)$. Although the phrasing of the corresponding questions in the two surveys is not exactly equal, a rough comparison of trends can be made for the questions involved. As an example, figure 9 shows a comparison between the two surveys for the question about physically demanding work. Both curves tend to decrease with age. The complaint percentages of the POHS respondents are lower than those of the general population, which may be because of differences in the context of the survey and regional influences on the complaint percentages due to sociocultural factors independent of work characteristics. ${ }^{2021}$ Almost all of the comparisons between corresponding questions from the two surveys show these differences between the two surveys as well as similarities in the relation between age and the prevalence of complaints.

Socioeconomic inequalities can influence the differences in health complaints between social groups, independently of work characteristics. ${ }^{22}$ Non-occupational factors related to socioeconomic group might influence the complaint percentages. For example, smoking, associated with both back pain and lower socioeconomic group, ${ }^{23}{ }^{24}$ might cause a higher background level of backache in lower socioeconomic groups, independently of their specific working conditions. Not only causal factors for diseases but also health problems may result in differences between social groups in health complaint percentages. Demanding factors in an occupation can also enhance the annoyance of an already existing health problem. For instance, if two employees have the same ankle injury, and one of them has a job that has to be performed standing while the other has the option of sitting during work, then the first employee will more readily indicate a complaint about pain in the ankle. Higher complaint percentages of the blue collar workers may partly be attributed to these conditional relations, especially in the case of the complaints of the musculoskeletal system. Therefore, interpreting the results of the health questions, one always has to keep in mind that the probability of whether an employee complains about a particular health problem will partly depend on the interaction between that (existing) health problem on the one hand and work and working conditions on the other.

The questions about work and working conditions are mainly questions about annoyance, and we assume that these questions refer to a comparable experience in the four social groups. To measure the annoying factor itself, one can better use other measurement instruments-for example, a personal noise dose meter or a personal air sampler for exposure to chemical substances. For many work problems no easy to handle instruments of objective measurement are available-for example, in the case of noise annoyance, time pressure, and the experienced quality of the management. 


\section{Conclusion}

Several aspects of the work capacity of employees decrease with age, as is stated in the introduction. Our own results indicated that the prevalence of health complaints and of (treatment for) diseases increase as age advances - for example, musculoskeletal complaints and treatment for musculoskeletal complaints. The task demands and working conditions were in general not age related. A general and systematic decrease of capacity without a comparable systematic decrease of task demands ${ }^{23}$ makes one expect a growing effort from the aging employee to cope with these task demands. No increase of complaints about the task demands and about the working conditions was found. This phenomenon can probably not (fully) be accounted for by the increased experience and the superior work strategy of the older workers. A plausible additional explanation is that the aging working population is healthy, especially in the oldest age groups and in strenuous occupations. Furthermore, through self selection and company policy, older employees will not be working in the most strenuous working situations. The job may be altered by a decrease of some of the task demands or an alteration of the task composition of the job. Furthermore, it is possible that the decision latitude of the aging employees is relatively high, which enables them to regulate their own momentary work load more or less according to their present working capacity.

Further research is needed to investigate whether these explanations of the limited increase of work complaints with age hold. The health, working conditions, and decision latitude of aging employees who leave their job can be compared with those of the employees remaining. The results of these studies can be used to select and stimulate measures that can be effectively used to enhance the work participation of the older employees-for example, reduction of task demands or an increase in decision latitude. In the future, these measures might help to decrease the high complaint percentages of the aging employees, as well as to reduce the health related turnover, especially in strenuous working situations.

1 Dehn MM, Bruce RA. Longitudinal variations in maximal oxygen intake with age and activity. $\mathcal{f} A p p l$ Physio oxygen intake

2 Shephard RJ. Human rights and the older worker: changes in work capacity with age. Med Sci Sport Exerc 1987 19:168-73.

3 Nygård C-H, Luopajärvi T, Ilmarinen J. Muscoloskeletal capacity and its changes among ageing municipal Environ Health 1991;17(suppl 1):110-7.
4 Cremer R. Cognitive ageing, visual task-demands and noise. Amsterdam: Studiecentrum Arbeid en Gezondheid, Universiteit van Amsterdam, 1993.

5 Cremer R. Matching vocational training programmes to age-related mental change-a social policy objective. In Snel J, Cremer R, eds. Work and aging: a European perspective. London: Taylor and Francis, 1994

6 van Dijk FJH, Dormolen M, Kompier MAJ, Meijman TF Herwaardering model belasting-belastbaarheid (revaluation model "work demands-work capacity"). Tijdschrift voo Sociale Gezondheidszorg 1990;68:3-10.

7 GMD. Statistische informatie 1992 (Statistical information 1992). Amsterdam: GMD, 1993.

8 Meulenbeld C. Peilstation PBGO io: verslag van een enquête onder de enkelvoudige bedriifsgezondheidsdiensten en basisgezondheidsdiensten in Nederland (Information Centre POHS starting up: report of a survey among occupational health services and basic health services in the Netherlands). health services and basic health services in the Netherlands). Amsterdam: Nederlar

9 Weel ANH, Broersen JPJ, van Dijk FJH. Periodical occupational health surveys: a refererence population as a control group. Am f Ind Med 1995;(submitted).

10 Broersen JPJ, van Dijk FJH, Weel ANH, Verbeek JHAM. The atlas of health and working conditions by occupation. (1) Occupational ranking lists and occupational profiles from periodical occupational health survey data. Int Arch Occup Environ Health 1995;(in press).

11 Broersen JPJ, Zwart BCH de, Meijman TF, van Dijk FJH, van Veldhoven M, Schabracq MJ. Veroudering, Werk en Gezondheid. Inventarisatie van klachten over werk en gezondheid (Ageing, work and health. List of complaints about work and health). Amsterdam: Studiecentrum Arbeid en Gezondheid, Universiteit van Amsterdam, Arbeid

12 Jenniskens PAH. Modelleren van bedrïfsgezondheidszorg (modeling of occupational health care). Breda: Stichting Bedrijfsgezondheidszorg West-Brabant, 1982

13 Central Bureau of Statistics. Beroepenclassificatie 1984 (Classification of occupations 1984). Voorburg: Central Bureau of Statistics, 1984

14 Bakker BFM, Jonker JK. Sociale groep; indeling en afleiding (Social group; classification and derivation). Central Bureau of Statistics-nota. Voorburg:CBS, 1986.

15 Rabbitt PMA, Carmichael A. Designing communications and information-handling systems for elderly and disabled users. In: Snel J, Cremer R. Work and aging: a European perspective. London: Taylor and Francis, 1994

16 Winter CR de. Arbeid, gezondheid en verzuim als voorspeller van uitval uit het werk (Work, health and sickness absence as predictors of outflow from jobs). Leiden: Nederlands Instituut voor Praeventieve Gezondheidszorg, 1991.

17 Stuurgroep Toekomstscenario's Gezondheidszorg (STG) Arbeid, gezondheid en welzijn in de toekomst. Toekomstscenario's arbeid en gezondheid 1990-2010. (Work health and well-being in the future. Prospects work and health 1990-2010). Houten: Bohn Stafleu Van Loghum, 1991.

18 Checkoway H, Pearce N, Crawford-Brown DJ. Research methods in occupational epidemiology. New York: Oxford methods in occupational

19 Central Bureau of Statistics. De leefsituatie van de Nederlandse bevolking (The living conditions of the Dutch Nederlandse bevolking (The living

20 Sonsbeek JLA van. Gezondheidsverschillen in regionaal perspectief (Health differences in a regional perspective). Voorburg: Central Bureau of Statistics, Maandberich Gezondheidsstatistiek, 1987.

21 Broersen JPJ, Weel ANH, van Dijk FJH, Verbeek JHAM Bloemhoff A, van Duivenbooden JC. The atlas of health and working conditions by occupation. (2) A comparison with the atlas of health and working conditions in the construction industry. Int Arch Occup Environ Health 1995; (in press)

22 Mackenbach JP. Socio-economic health differences in the Netherlands: a review of recent empirical findings. Soc Sci Med 1992;34:213-26.

23 Riihimäki $H$, Wickström $G$, Hänninen $K$, Luopajärvi $T$. Predictors of sciatic pain among concrete reinforcement Predictors of sciatic pain among concrete reinforcement workers and house painters-a five-year
$\mathcal{f}$ Work Environ Health 1989;15:415-23.

24 Boshuizen HC, Verbeek JHAM, Broersen JPJ, Weel ANH Do smokers get more back pain? Spine 1993;18 $35-40$.

25 Ilmarinen J. Aging, work and health. In: Snel J, Cremer R Work and aging: a European perspective. London: Taylor and Francis, 1994.

\section{Rejected manuscripts}

From February 1994, authors whose submitted articles are rejected will be advised of the decision and one copy of the article, together with any reviewers' comments, will be returned to them. The fournal will destroy remaining copies of the article but correspondence and reviewers' comments will be kept. 